\title{
Who are the leaders?
}

$\mathrm{W}$

hy are you going to Papua New Guinea? Don't you know that after Baghdad, Port Moresby is the second most dangerous city in the world?" When a concerned friend from the World Bank asked me this, I realized my briefing papers had left out these frightening details: women face a 1 in 2 lifetime risk of rape, health teams doing outreach patrols for immunization are often attacked, a third of the rural aid-posts have closed - largely due to increasing insecurity, and this is the worst country for HIV/AIDS in the South Pacific.

Nevertheless, I had to go. As part of our work in the Independent Monitoring and Review Group (funded by the governments of Papua New Guinea, New Zealand and Australia and the UN), we go twice a year to track progress, or the lack of it, in the health sector. Mark, an Australian, Yvonne, a Papua New Guinean, and I were assigned to a poor province that was not doing well.

To reach the boat for our journey by river we had to cross from the wharf to the shore, but the bridge had washed out. High above the water there was an impromptu foot bridge - 2 very narrow flattened logs, 4.6 metres long, connected to a foot square platform - then another 4.6 metres of logs to the next platform, for a total of 4 sections. There was barely space to place 1 sandal-clad foot on each $\log$. The other side looked impossibly far away. I was anxious. The first to cross was the competent, relaxed Mark with his backpack and easy manner. Next was Ruben, the Papua New Guinean district family health coordinator. I watched the narrow logs bend and sway under each person's weight. I looked at my pile of papers, my handbag and, worried about the need to balance with both my arms, accepted Mark's offer as he reached back to carry my reports. Ruben also looked back at me as I looked down uncertainly at the rolling, boiling waters and rocks. I was sure I couldn't do this. Ruben smiled and reached out to me. I took his hand,

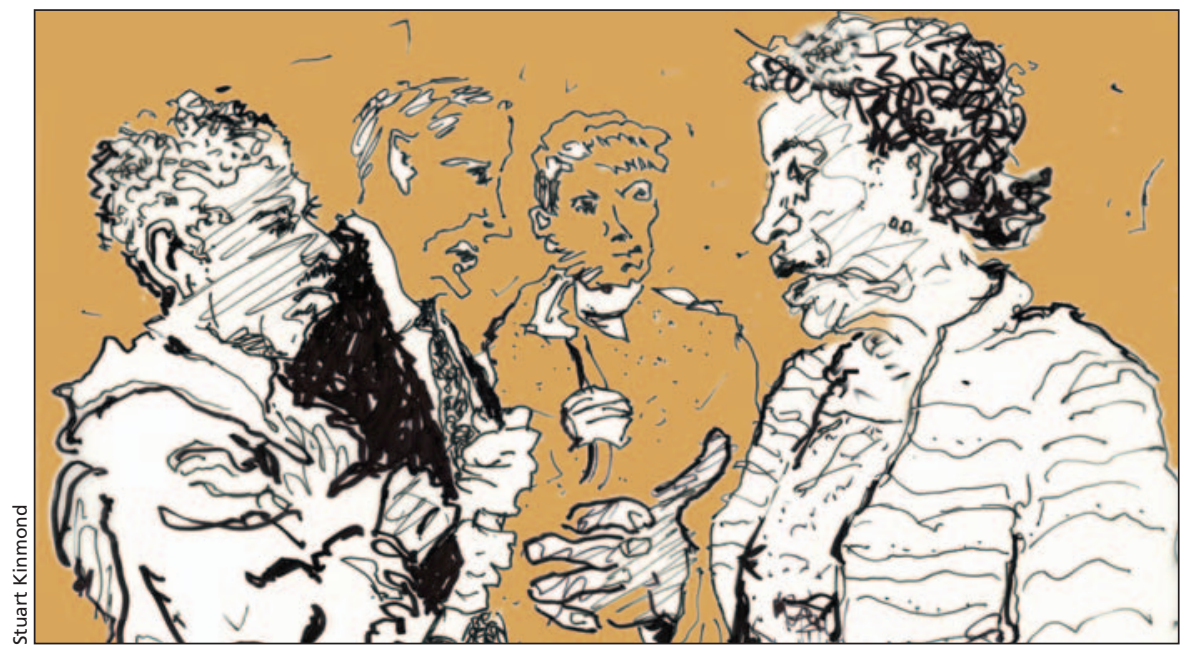

warm and comforting, as he led me across the shaky surface to the first landing. My mind was completely centred, with the secure feel of his larger palm holding mine, this man I had met only 10 minutes before. We had 3 more sections to cross. Ruben led.

As I followed, I thought to myself, this is really how it is. We foreign-aid types think that our technical assistance has us in the leading role, but we are the ones following and learning in this new culture and challenging environment. I tried not to look down as we slowly inched our way across. Finally, we jumped down to the squelching mud flats on the river shore and walked barefoot through the mud that oozed between our toes. We rinsed off our feet at the dinghy and greeted our driver.

The Marua River winds its serpentine way, with tropical rainforest on either shore. Palm trees stretch up several storeys, their vine leaves as broad as my arm curving up their trunks. In some areas mangroves grow, sheltering sago trees, which provide the source of a popular staple. On the shore we saw women making sago and stopped to watch. Two trees, a metre long each, had been cut open and laid diagonally on a brace. The women scooped and pounded the inner pulp. River water was poured into the mash continually, as a thick orange liquid sieved through a leaf and rush funnel into a dug-out container at the bottom of the sluice. Two women, 2 sago trees, the pounding in unison. By the next day the amber liquid would have hardened into a thick crusty porridge to be cooked into a crumbly staple biscuit.

As I watched, the thoughts I'd had while crossing the river coalesced. Developing countries can, and must, lead the process of change. Local communities have, and use, knowledge that has helped them survive. As we all struggle with corrupt leaders, faltering progress in the Millennium Development Goals, including poverty and mortality reduction, we need to be reminded that our role is to strengthen and catalyze local, national and regional leadership to solve these overwhelming problems.

\section{Gretchen Roedde MD}

Family physician

International reproductive health care consultant

Temiskaming Shores, Ont.

Dr. Roedde has worked for 2 decades in over 25 countries to reduce HIV and maternal and child mortality.

Have you got an opinion about this article? Post your views at www.cmaj.ca. Potential Salon contributors are welcome to send a query to salon@cma.ca. 